\title{
Fine Structure of Spore Formation and Germination in Micromonospora chalcea
}

\author{
By CARLOS HARDISSON AND JUAN EVARISTO SUÁREZ \\ Departamento de Microbiología, Universidad de Oviedo, Oviedo, Spain
}

(Received 14 September 1978)

INTRODUCTION

The genus Micromonospora contains filamentous bacteria which form a monopodially branched mycelium from one asexual spore. Spores are produced on this mycelium and, under appropiate conditions, these germinate and repeat the cycle.

The fine structure of the genus was studied by Luedemann \& Casmer (1973) who related the mycelial and spore structure seen in thin sections to the silhouettes obtained by the electron microscopy of whole mounts. They presented electron micrographs of different stages of sporogenesis in $M$. chalcea, but all of them after the formation of the sporulation septum. The ultrastructure of sporogenesis was studied in $M$. globosa and $M$. fusca by S tevens (1975), and Sharples \& Williams (1976) have described the ultrastructure of spore germination in $M$. melanosporea. However, we know of no previous studies of both sporogenesis and germination in the neotype strain $M$. chalcea.

\section{METHODS}

Culture conditions. Micromonospora chalcea ATCC 12452, neotype strain, (Luedemann, 1971) was inoculated by streaking on GAE solid medium (Hardisson \& Manzanal, 1976) in Petri dishes and incubated at $28^{\circ} \mathrm{C}$. After 6 to $12 \mathrm{~d}$, well-isolated colonies were selected for an ultrastructural study of sporulation.

Preparation of spore suspensions. Organisms were grown for $20 \mathrm{~d}$ at $28{ }^{\circ} \mathrm{C}$ in $250 \mathrm{ml}$ flasks containing $75 \mathrm{ml}$ GAE broth, and spore suspensions were prepared as previously described (Hardisson et al., 1978).

Germination. Recently harvested spore suspensions were germinated as described previously (Hardisson et al., 1978). Spores at different stages of germination (dormant, swollen and spores with germ tubes), as revealed by phase-contrast microscopy, were selected.

Electron microscopy. Samples for the study of sporulation and germination were treated as previously described (Hardisson \& Manzanal, 1976; Hardisson et al., 1978) except that they were stained with uranyl acetate for $30 \mathrm{~min}$ and poststained with lead citrate (Reynolds, 1963) for $4 \mathrm{~min}$. Photographs were taken with a Philips EM-300 electron microscope operating at $80 \mathrm{kV}$.

\section{RESULTS}

Sporulation septum formation. The early stages of sporogenesis in $M$. chalcea were characterized by a lateral or apical swelling of a hypha and the formation of a sporulation septum (Fig. $1 a, b, c, d$ ). The sporulation septum had a three-layered structure similar to that of the vegetative cross-wall (Fig. $1 a$ ) from the onset of the process (Fig. 1b). Mesosomes were associated with the developing septum and the nuclear region (Fig. $1 a, b, c, d$ ). Warts were observed on the developing spore wall before completion of the sporulation septum (Fig. $1 b, c$ ) but more clearly after its completion (Fig. $1 d$ ). The cytoplasmic membrane seemed to follow the contours of the warts (Fig. 1d).

Spore maturation. After completion of the sporulation septum, a series of changes transformed the newly delimited swollen hyphal tip into a mature spore. There was a 

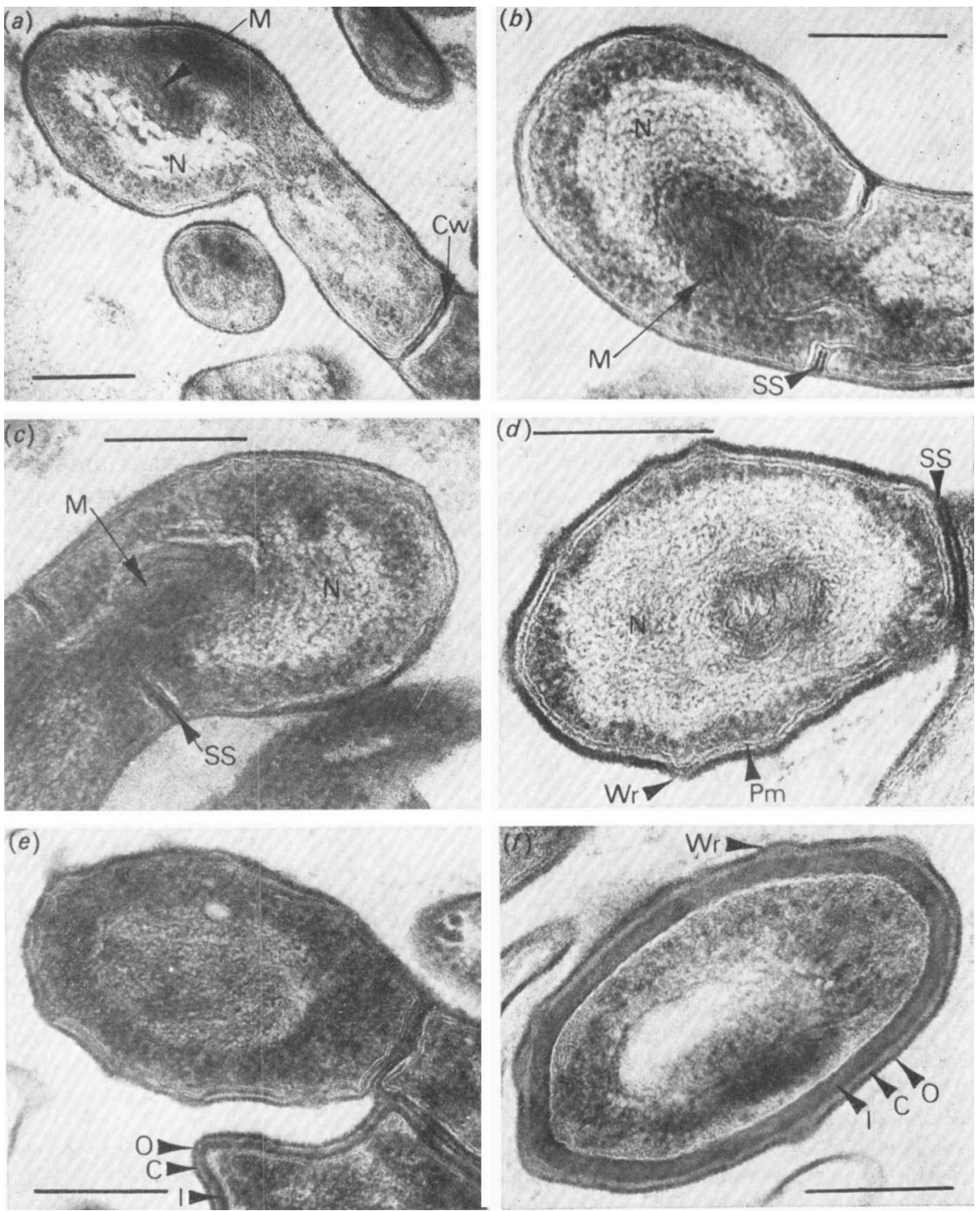

Fig. 1. Sporogenesis in Micromonospora chalcea: $\mathrm{Cw}$, vegetative cross-wall; $\mathrm{N}$, nuclear material; $\mathrm{M}$, mesosome; Wr, wart; SS, sporulation septum; Pm, plasma membrane; O, outer spore wall; C, medial spore wall; I, inner spore wall. Bar markers represent $200 \mathrm{~nm}$.

(a) Initiation of sporogenesis by the swelling of the apical end of a hypha. A vegetative crosswall showing a three-layered structure and nuclear material associated with a mesosome may be seen.

$(b, c)$ Initial stages of sporulation septum formation. A mesosome is associated with the sporulation septum and with the nuclear material. Note the three-layered structure of the septum.

(d) A newly delimited spore showing a mesosome associated with the nuclear region and several warts on the original hyphal wall. The plasma membrane evaginates at the site of the warts.

(e) Spores in an early stage of maturation. The spore wall shows a three-layered structure, but all the layers are approximately equal in width.

( $f$ ) Mature spore after release showing an inner, thick and electron-dense layer, a middle less electron-dense layer and an outer, thin and electron-dense layer. No structures can be seen within the cytoplasm. 

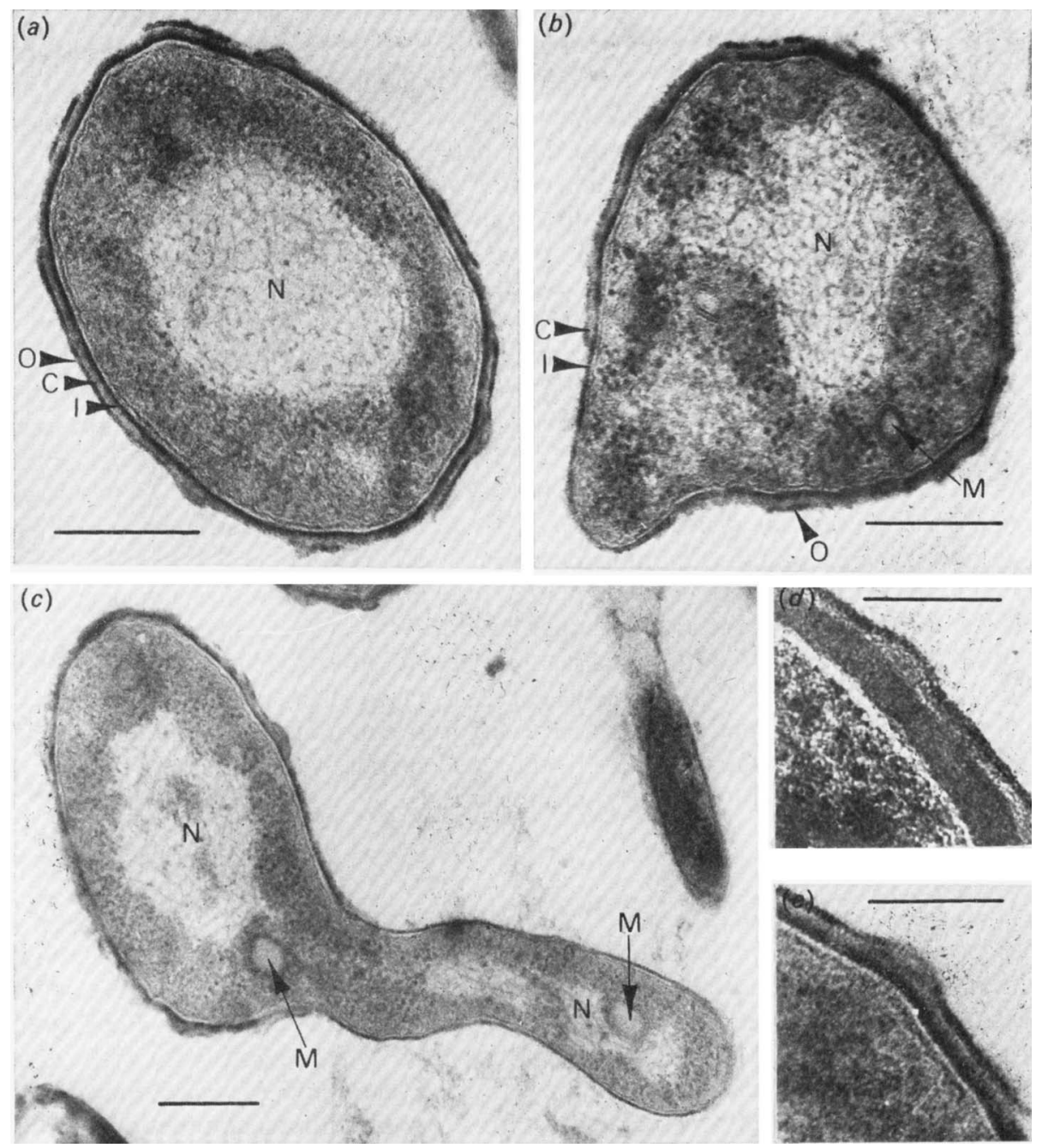

Fig. 2. Spore germination in Micromonospora schalcea: symbols as in Fig. 1. Bar markers represent $200 \mathrm{~nm}$, except where indicated.

(a) Swollen spore showing the cytoplasmic membrane, nuclear material, abundant ribosomes and spore wall. The rigid outer spore wall layer has broken at several points.

(b) Germinating spore at an early stage of germ tube emergence. Note the continuity of the germ tube wall with the inner layer of the spore wall. Mesosomes may be seen as simple membranous pouches.

(c) Spore with a well developed germ tube having two nuclear regions, one of which has moved out to the germ tube and is associated with a mesosome.

$(d, e)$ Enlarged detail of the spore wall in a dormant spore and in a swollen spore, respectively. Note the difference in width of the inner layers. (Bar markers represent $100 \mathrm{~nm}$.)

centripetal deposition of wall material to form different layers (Fig. $1 e, f$ ). The final mature spore had a wall comprising three zones of different electron densities: an outer electrondense layer (about 7 to $8 \mathrm{~nm}$ ), an intermediate less electron-dense layer (about $11 \mathrm{~nm}$ ) and an inner electron-dense layer (about 25 to $26 \mathrm{~nm}$ ). The thickness of the entire wall was about $44 \mathrm{~nm}$. The diameter of the dormant spore was about 0.38 to $0.40 \mu \mathrm{m}$ and its surface area was about $0 \cdot 115$ to $0 \cdot 125 \mu \mathrm{m}^{2}$. As maturation proceeded, the cytoplasmic structures of the spore, such as mesosomes, DNA and ribosomes, became less visible, probably because the fixatives could not penetrate the spore. 
Germination. The first visible change in ultrastructure during germination coincided with the swelling stage (Fig. $2 a$ ). The spore diameter increased to between 0.54 and $0.56 \mu \mathrm{m}$ and its surface area to about 0.23 to $0.25 \mu \mathrm{m}^{2}$. Probably because of an increase in the permeability of the spore wall at this stage, the cytoplasmic structures were clearly seen. The thickness of the entire wall decreased to between 21 and $23 \mathrm{~nm}$ and, although the three-layered structure of the dormant spore wall was conserved, its appearance was quite different. The outer layer, probably because of its rigidity, was broken at numerous points as a consequence of the spore swelling, although it preserved the same electron density and thickness as observed in the dormant spore. The intermediate, less electron-dense layer also apparently remained unchanged, while the inner layer was noticeably thinner $(9 \mathrm{~nm})$ than in the dormant stage. It was this inner layer which extended and emerged through the outer layers to form the germ tube wall (Fig. $2 b$ ). The nuclear region in germinating spores had an irregular shape without defined boundaries (Fig. $2 b, c$ ). Mesosomes were not frequent during these early stages of germination; when present, they were simple membranous pouches (Fig. $2 b, c$ ), often in association with the nuclear material.

Changes in dimensions of spores and their walls during germination. During swelling, the spore perimeter increased and, simultaneously, the thickness of the wall changed from about $44 \mathrm{~nm}$ to about 21 to $23 \mathrm{~nm}$. To estimate if stretching of the wall alone is sufficient to cover the enlarged surface area of the swollen spore, Gull \& Trinci (1971) proposed the equation: $t_{s}=t_{\mathrm{d}} \times(100 / S)$, in which $t_{\mathrm{s}}$ is the thickness of the wall after swelling, $t_{\mathrm{d}}$ the thickness of the dormant spore wall and $S$ is the surface area of the swollen spore, expressed as a percentage of the dormant spore surface area. Using this equation the estimated value for $t_{\mathrm{s}}$ $(22 \mathrm{~nm})$ was close to the value observed for the swollen spore wall indicating that synthesis of new wall material was not necessary during swelling.

\section{DISCUSSION}

Sporogenesis in $M$. chalcea occurs in two stages, sporulation septum formation and spore maturation. The process is initiated by the swelling of the apical end of a hypha before its delimitation by the sporulation septum. Mesosomes are associated with the DNA and with the formation of the sporulation septum, as has been reported previously for other bacteria (Ryter, 1968; Greenawalt \& Whiteside, 1975). In $M$. globosa and $M$. fusca, Stevens (1975) did not find mesosomes directly associated with the septum until its completion. As Luedemann \& Casmer (1973) pointed out, warts are formed on the spore wall before the deposition of the material of the new layers of the spore wall has begun. Perhaps the origin of the warts is linked to the swelling of the hyphal tip at the beginning of sporogenesis. The swelling of a hypha will need the participation of enzymes involved in wall lysis and synthesis. It is possible that warts are points of preferential wall attack and synthesis with less mechanical resistance. The sporulation septum has a typical three-layered structure similar to that of the vegetative cross-wall, as has been reported previously in $M$. chalcea (Luedemann \& Casmer, 1973) and in $M$. fusca and $M$. globosa (Stevens, 1975). The structure of the sporulation septum and its process of formation is similar to that of Streptomyces type I (Hardisson \& Manzanal, 1976). However, the vegetative cross-walls in Streptomyces are formed by a septum of uniform electron density (Glauert \& Hopwood, 1961 ; C. Hardisson \& M. B. Manzanal, unpublished results), and the process of spore maturation is different. In Streptomyces (Manzanal \& Hardisson, 1978) no layers are discernible in the spore wall, whereas in the mature spores of $M$. chalcea there is a stratified deposition of materials with different electron density.

The ultrastructural changes that accompany the germination of $M$. chalcea spores are similar to those found in Streptomyces (Hardisson et al., 1978). In both cases it is the inner layer of the stratified spore wall which forms the wall of the germ tube. However, in Strep- 
tomyces the spore wall only appears stratified after swelling. In both cases the nuclear material is irregular in shape without defined boundaries, an aspect that corresponds to the DNA in active transcription (Ryter \& Chang, 1975). The structure of the germinated spore is different from that found in M. melanosporea (Sharples \& Williams, 1976) in which cross-walls develop soon after the emergence of the germ tube, and the cytoplasm of the spore shows abundant spherical electron-light areas; these were never observed in germinated spores of $M$. chalcea.

The swelling of the spore is apparently not accompanied by the synthesis of new wall material. The stretching of the inner layer in the dormant spore accounts for the increase in surface area. Similar results were found in M. melanosporea (Sharples \& Williams, 1976).

The authors wish to thank Dr T. Cross, Postgraduate School of Studies in Biological Sciences, University of Bradford, for helpful discussions and critical reading of the manuscript. J.E.S. was the recipient of a predoctoral fellowship from the Ministry of Education of Spain.

\section{REFERENCES}

Glauert, A. M. \& Hopwood, D. A. (1961). The fine structure of Streptomyces violaceoruber (S. coelicolor) III. The walls of the mycelium and spores. Journal of Biophysical and Biochemical Cytology 10, 505-516.

Greenawalt, J. W. \& Whiteside, T. L. (1975). Mesosomes. Membranous bacterial organelles. Bacteriological Reviews 39, 405-463.

Gull, K. \& Trinci, A. P. J. (1971). Fine structure of spore germination in Botrytis cinerea. Journal of General Microbiology 68, 207-220.

Hardisson, C. \& Manzanal, M. B. (1976). Ultrastructural studies of sporulation in Streptomyces. Journal of Bacteriology 127, 1443-1454.

Hardisson, C., Manzanal, M. B., Salas, J. A. \& SuÁrez, J. E. (1978). Fine structure, physiology and biochemistry of arthrospore germination in Streptomyces antibioticus. Journal of General Microbiology 105, 203-214.

LuedemanN, G. M. (1971). Designation of neotype strains for Micromonospora coerulea Jensen 1932 and Micromonospora chalcea (Foulerton 1905) Ørskov 1923. International Journal of Systematic Bacteriology 21, 248-253.

LuedemanN, G. \& Casmer, C. J. (1973). Electron microscope study of whole mounts and thin sections of Micromonospora chalcea ATCC 12452. International Journal of Systematic Bacteriology 23, 243-255.

Manzanal, M. B. \& Hardisson, C. (1978). Early stages of arthrospore maturation in Streptomyces. Journal of Bacteriology 133, 293-297.

REYNOLDS, E. S. (1963). The use of lead citrate at high $\mathrm{pH}$ as an electron-opaque stain in electron microscopy. Journal of Cell Biology 17, 208-212.

RYTER, A. (1968). Association of the nucleus and the membrane of bacteria: a morphological study. Bacteriological Reviews 32, 39-54.

RYTER, A. \& CHANG, A. (1975). Localization of transcribing genes in the bacterial cell by means of high resolution autoradiography. Journal of Molecular Biology 98, 797-810.

Sharples, G. P. \& Williams, S. T. (1976). Fine structure of spore germination in actinomycetes. Journal of General Microbiology 96, 323-332.

SteVENs, R. T. (1975). Fine structure of sporogenesis and septum formation in Micromonospora globosa Kriss and $M$. fusca Jensen. Canadian Journal of Microbiology 21, 1081-1088. 